\title{
Effects of Intrathecal Caffeic Acid Phenethyl Ester (CAPE) on IL- 6 and TNF- $\alpha$ Levels and Local Inflammatory Responses in Spinal Cord Injuries
}

\author{
Bekir AKGUN ${ }^{1}$, Sait OZTURK¹, Gokhan ARTAS ${ }^{2}$, Fatih Serhat EROL ${ }^{1}$ \\ ${ }^{1}$ Firat University, School of Medicine, Department of Neurosurgery, Elazig, Turkey \\ ${ }^{2}$ Firat University, School of Medicine, Department of Clinical Pathology, Elazig, Turkey
}

\section{ABSTRACT}

AIM: To investigate the effects of intrathecal caffeic acid phenethyl ester (CAPE) on tissue and serum interleukin-6 (IL-6) and tumor necrosis factor-alpha (TNF-a) levels following spinal cord injury (SCl) as well as its effects on edema and microhemorrhage.

MATERIAL and METHODS: Forty rats were divided into four groups. The sham group underwent single-level laminectomy and then received an intrathecal injection of isotonic saline. The control group received an intrathecal injection of isotonic saline following SCI induction. The methylprednisolone (MP) group received a single dose of MP intrathecally following SCI. The CAPE group received a single dose of CAPE intrathecally following SCI. IL-6 and TNF-a levels were determined using the enzyme-linked immunosorbent assay (ELISA) method. Spinal cord samples were evaluated histopathologically.

RESULTS: The decrease in IL-6 levels in the CAPE group was significantly higher than that in the sham and control groups. However, this decrease was not as significant as that in the MP group. No significant decrease was identified in TNF-a levels. A significant decrease was observed in spinal cord edema and microhemorrhage in the CAPE group. A decrease in edema was observed in the MP group, but no effect was observed on microhemorrhage.

CONCLUSION: Intrathecal CAPE administration following SCI decreases tissue and serum IL-6 levels as well as decreases spinal cord edema and microhemorrhage.

KEYWORDS: Caffeic acid phenethyl ester, Histopathology, IL-6, Spinal cord injury, TNF-a

\section{INTRODUCTION}

$\mathrm{M}$ icroglia are known to produce inflammatory cytokines during ischemia-reperfusion damage following spinal cord injury (SCl), and these cytokines act as cytotoxic mediators (5). To decrease or altogether prevent secondary damage following $\mathrm{SCl}$, the prevention and inhibition of inflammatory cytokines and/or their cytotoxic characteristics must be considered during treatment.

Caffeic acid phenethyl ester (CAPE) is a propolis component obtained from honeybee hives, and it shows antioxidant and anti-inflammatory properties. It has been previously demonstrated that CAPE affects inflammation by potently and specifically inhibiting the activity of the nuclear transcription factor NF-k $\beta$, a transcription factor of CAPE (8).

$N F-k \beta$ induces cytokine expression during the inflammatory response. It has been shown that CAPE decreases the expression of inflammatory cytokines such as IL-1-a, IL-1- $\beta$, IL-6, tumor necrosis factor-alpha (TNF-a), and transforming growth factor-beta (TGF- $\beta$ ) through its inhibitory effects on NF$\mathrm{kB}$ activation and those on the production of pro-inflammatory agents (3). 
The inflammatory response associated with $\mathrm{SCl}$ plays a significant role in secondary spinal cord damage. The effects of pro-inflammatory cytokines and inflammatory enzymes during inflammatory response are well known $(7,8)$. Cytokines are effective in activated leukocyte-dependent endothelial cell damage and direct endothelial cell damage. These mechanisms result in edema and microhemorrhage in the damaged area because of capillary endothelial damage and increased vascular permeability $(6,11,13)$.

It has been experimentally demonstrated that the antioxidant properties of CAPE could potentially have protective effects against spinal cord ischemia-reperfusion damage $(4,5)$. In addition, some studies have investigated the anti-inflammatory effects of systemic CAPE administration (1).

In this study, we evaluated the effects of intrathecal CAPE administration on tissue and serum IL- 6 and TNF-a levels following $\mathrm{SCl}$. In addition, we discussed the role of CAPE in preventing edema and microhemorrhage that develop following $\mathrm{SCl}$ through its effects on these cytokines.

\section{MATERIAL and METHODS}

\section{Animals and Study Groups}

Following approval (approval date: Feb 17, 2016 and approval number: 04/16) by the Animal Research Ethics Committee of our university, 40 female mature Wistar rats who had normal motor activity, weighed between 220 and $260 \mathrm{~g}$, and were approximately 9 or 10 weeks old were included in the study. The animals were supplied from the Experimental Animals Implementation and Research Center of our university. The rats were housed in standard laboratory conditions (a 12-h light/dark cycle; room temperature between $20^{\circ} \mathrm{C}$ and $22^{\circ} \mathrm{C}$ ). The study groups were as follows:

Sham group: The group only underwent single-level laminectomy and then received intrathecal administration of $10 \mu \mathrm{L}$ isotonic saline $(\mathrm{n}=10)$.

Control group: The group was intrathecally injected with 10 $\mu \mathrm{L}$ of isotonic saline following $\mathrm{SCl}$ induction $(n=10)$.

Methylprednisolone (MP) group: The group was administered a single dose of $3 \mathrm{mg} / \mathrm{kg}$ methylprednisolone intrathecally following $\mathrm{SCl}$ induction $(\mathrm{n}=10)$.

CAPE group: The group was administered a single dose of 1 $\mu \mathrm{g} / \mathrm{kg}$ CAPE intrathecally following $\mathrm{SCl}$ induction $(\mathrm{n}=10)$.

\section{Surgical Procedure}

All the rats were anesthetized with $50 \mathrm{mg} / \mathrm{kg}$ (im) ketamine hydrochloride (Ketalar, Pfizer, Istanbul, Turkey) and $10 \mathrm{mg} / \mathrm{kg}$ (im) xylazine (Rompun, Bayer, Istanbul, Turkey) in a manner that ensured the maintenance of spontaneous respiration. A $3 \times 2 \mathrm{~cm}$ area on the back of the rats was shaved, and local antisepsis was applied with povidone iodine. At the T5-T12 level, the skin, subcutaneous tissues, and paravertebral muscle fascia were opened. The muscle tissues were then peeled laterally by blunt dissection, enabling the visualization of the T7-T10 laminae. After taking precautions to avoid dura mater damage, single-level total laminectomy was performed using a surgical microscope. The dura and spinal cord of rats other than the ones in the sham group were clipped for 1 minute with Yasargil aneurysm clips (Aesculap FE $721 \mathrm{~K}$ ), which exerted approximately a $63 \mathrm{~g}$ force around the spinal tissue. Following hemostasis, the incision area was closed with $3 / 0$ silk. For intrathecal administration, intrathecal catheterization was performed using a polyethylene tube (P.E.; inner diameter $0.28 \mathrm{~mm}$ and outer diameter $061 \mathrm{~mm}$, Becton Dickinson, Philadelphia, USA)(9,12). Drug and saline administration according to the groups was performed through the intrathecal catheter using a Hamilton injector (Hamilton Bonaduz AG, Bonaduz, Switzerland). The catheter was washed with saline following drug administration. The animals were warmed by keeping them over electric heater pads during and immediately after surgery. The body temperatures of the test rats were maintained at $37^{\circ} \mathrm{C}$ by monitoring using a rectal heat probe. Blood was collected from the tails of the animals 18 hours after the operation. All the rats in the study were killed by overdose of pentobarbital 48 hours after the operation. In total, $2 \mathrm{~cm}$ of the spinal cord at the injury site was excised; the excision was performed $1 \mathrm{~cm}$ rostrally and $1 \mathrm{~cm}$ caudally to the injury site.

\section{IL-6 and TNF-a Levels}

The excised tissue samples were weighed and immediately stored at $-70^{\circ} \mathrm{C}$. The tissues were minced and homogenized in five volumes $(\mathrm{w} / \mathrm{v})$ of phosphate-buffered saline. Assays were performed on the supernatant of the homogenate, which was prepared at $14,000 \mathrm{rpm}$ for 30 minutes at $+4^{\circ} \mathrm{C}$. The plasma IL-6 and TNF-a (Bender Med Systems, Vienna, Austria) levels were determined using the enzyme-linked immunosorbent assay (ELISA) method.

\section{Histopathological Examinations}

For histopathological examinations, spinal cord samples were fixed in $10 \%$ neutral-buffered formalin and stored at $4^{\circ} \mathrm{C}$ for 1 week, following which they were placed in fresh fixative. Fixed tissue samples were embedded in paraffin and horizontally sectioned into $5-\mu \mathrm{m}$ slices using a microtome. After deparaffinization, the sections were mounted on slides and stained with hematoxylin and eosin (H\&E). The slides were assessed under a light microscope for edema, microhemorrhage, and necrosis. The scoring for edema and microhemorrhage is as follow:

Edema $($ none $=0 /$ slight $=1 /$ moderate $=2 /$ pronounced $=3$ )

Microhemorrhage (none $=0 /$ one-two focal points $=1 /$ more than two focal points=2/ widespread bleeding=3)

Ten microscopic fields from gray matter at $100 \times$ magnification were randomly selected.

\section{Statistical Analysis}

Statistical analysis was performed by SPSS for Windows 13.0 (SPSS Inc., Chicago, IL, USA). Data were presented as mean values \pm standard deviations for biochemical values. Groups were compared using the non-parametric Kruskal-Wallis test. Mann-Whitney $U$ test was used for binary comparisons. $p$ values of less than 0.05 were considered significant. 


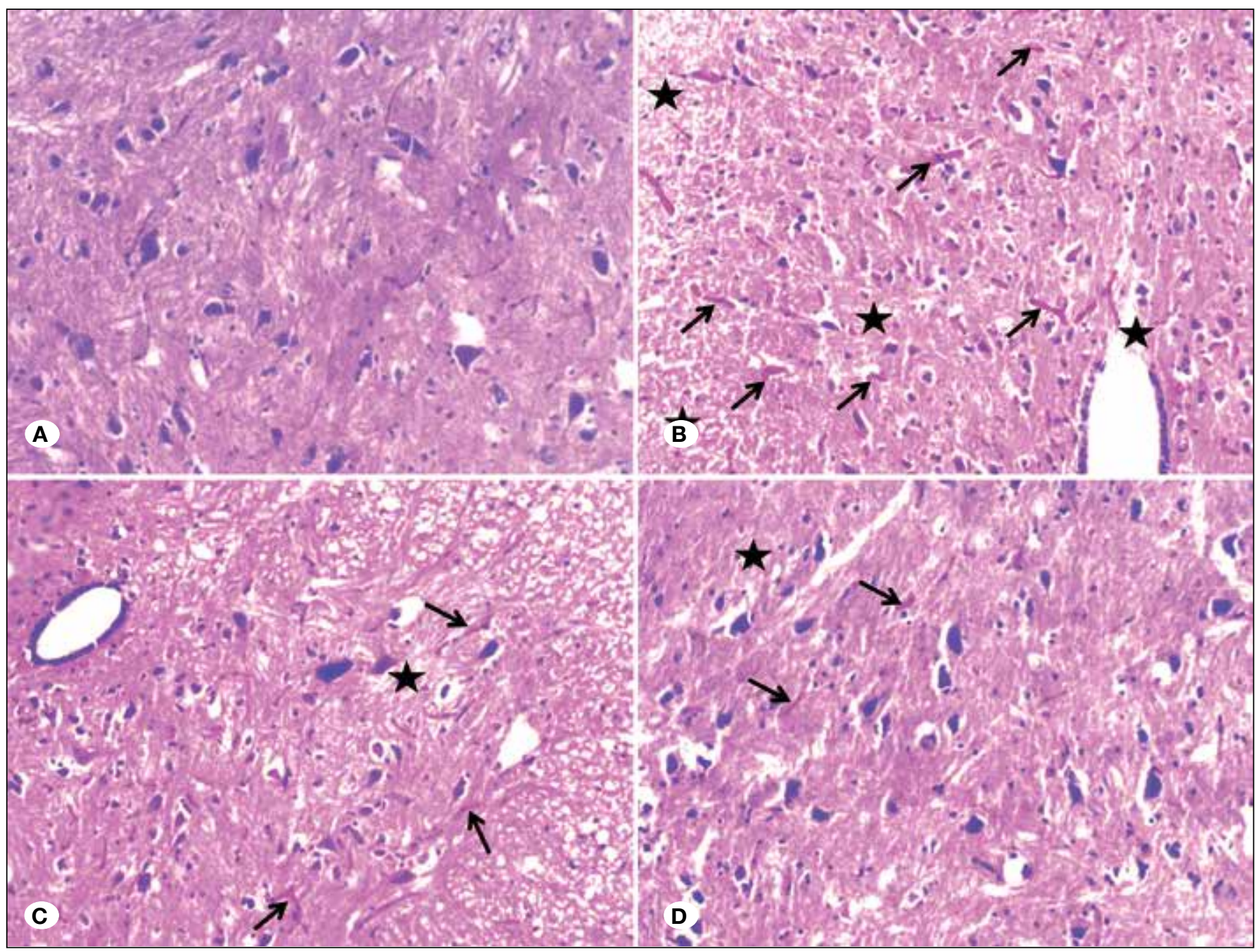

Figure 1: Histopathological photomicrographs, A) SHAM Group, B) CONTROL Group, C) MP Group, D) CAPE Group (H\&E, x200) (stars show edema, arrows show microhemorrhage).

\section{RESULTS}

Compared with the sham group, there was a significant increase in both tissue and serum IL-6 levels in the control group $(p<0.05)$. No significant difference was observed between the TNF-a levels in these two groups ( $p>0.05)$. Both tissue and serum IL-6 levels in the CAPE and MP groups were significantly lower than those in the sham group $(p<0.05)$ (Table I).

Tissue and serum IL-6 levels in the CAPE and MP groups were significantly lower than those in the control group $(p<0.05)$. However, CAPE was not as effective as MP in decreasing IL-6 levels. Tissue and serum TNF-a levels were also lower in the CAPE and MP groups than in control group. However, the difference in TNF-a levels was not significant ( $p>0.05$ ) (Table I).

During the histopathological evaluation of spinal cords, it was observed that the frequency of spinal cord edema significantly decreased in the CAPE and MP groups compared with the control group. A comparison of CAPE and MP revealed that
MP had no effect on bleeding. On the other hand, CAPE evidently and significantly decreased microhemorrhage (Table II and Figure 1A-D).

\section{DISCUSSION}

During post-traumatic $\mathrm{SCl}$, local inflammatory responses play a significant role in secondary damage. Pro-inflammatory cytokines lead to activated leukocyte-dependent endothelial cell damage. It has been previously reported that the prevention of activated neutrophils in the injury region and of interactions between endothelial cells significantly decreases the severity of damage $(10,11,13)$. It has also been demonstrated that the prevention and suppression of leukocyte-dependent inflammatory cells during the reperfusion process can lead to improved neurological function (5).

The effects of cytokines on endothelial cell damage are mediated by different mechanisms. It has been reported that through neutrophil activation, cytokines increase the release 
Table I: Biochemical Parameters according to the Groups

\begin{tabular}{llcccc}
\hline & Parameters & $\begin{array}{c}\text { SHAM } \\
\text { (Mean } \pm \text { SD) }\end{array}$ & $\begin{array}{c}\text { CONTROL } \\
\text { (Mean } \pm \text { SD) }\end{array}$ & $\begin{array}{c}\text { MP } \\
\text { (Mean } \pm \text { SD) }\end{array}$ & $\begin{array}{c}\text { CAPE } \\
\text { (Mean } \pm \text { SD) }\end{array}$ \\
\hline \multirow{2}{*}{ TISSUE } & IL-6 $(\mathrm{ng} / \mathrm{ml})$ & $1.82 \pm 0.19$ & $2.80 \pm 0.41^{\mathrm{a}}$ & $1.04 \pm 0.26^{\mathrm{a}, \mathrm{b}}$ & $1.42 \pm 0.17^{\mathrm{a}, \mathrm{b}, \mathrm{c}}$ \\
\cline { 2 - 7 } & TNF-a $(\mathrm{ng} / \mathrm{ml})$ & $10.47 \pm 1.09$ & $10.91 \pm 1.77$ & $8.97 \pm 0.50$ & $9.96 \pm 1.30$ \\
\multirow{2}{*}{ SERUM } & IL-6 $(\mathrm{ng} / \mathrm{ml})$ & $0.91 \pm 0.07$ & $1.48 \pm 0.13^{\mathrm{a}}$ & $0.31 \pm 0.09^{\mathrm{a}, \mathrm{b}}$ & $0.52 \pm 0.13^{\mathrm{a}, \mathrm{b}, \mathrm{c}}$ \\
\hline
\end{tabular}

SD: Standard deviation. a Significantly different from group SHAM $(p<0.05),{ }^{b}$ Significantly different from group CONTROL (p<0.05), ${ }^{c}$ Significantly different from group $M P(p<0.05)$.

Table II: Histological Parameters according to the Groups

\begin{tabular}{lcccc}
\hline Parameters & $\begin{array}{c}\text { SHAM } \\
\text { (Mean } \pm \text { SD) }\end{array}$ & $\begin{array}{c}\text { CONTROL } \\
\text { (Mean } \pm \text { SD) }\end{array}$ & $\begin{array}{c}\text { MP } \\
\text { (Mean } \pm \text { SD) }\end{array}$ & $\begin{array}{c}\text { CAPE } \\
\text { (Mean } \pm \text { SD) }\end{array}$ \\
\hline Edema & $0.70 \pm 0.48$ & $2.70 \pm 0.48^{\mathrm{a}}$ & $1.70 \pm 0.48^{\mathrm{a}, \mathrm{b}}$ & $1.80 \pm 0.63^{\mathrm{a}, \mathrm{b}}$ \\
\hline Microhemorrhage & $0.00 \pm 0.00$ & $2.00 \pm 0.67^{\mathrm{a}}$ & $2.00 \pm 0.65^{\mathrm{a}}$ & $1.20 \pm 0.63^{\mathrm{a}, \mathrm{b}, \mathrm{c}}$ \\
\hline
\end{tabular}

SD: Standard deviation. a Significantly different from group SHAM ( $p<0.05)$, ${ }^{b}$ Significantly different from group CONTROL ( $\left.p<0.05\right),{ }^{c}$ Significantly different from group $M P(p<0.05)$.

of endothelial leukocyte adhesion molecules that allow neutrophils to adhere to the endothelial cell surface. Cytokines also result in increased vascular permeability by causing direct endothelial cell lysis, independently of neutrophils $(10,13)$. Thus, edema and microhemorrhage develop in the area damaged by these previously reported direct and indirect mechanisms $(6,11)$. In the local inflammatory response, it has been demonstrated that pro-inflammatory mediators and in particular TNF-a and IL-6 are associated with neutrophil infiltration $(6,8,13)$.

Only a few studies have investigated the anti-inflammatory effects of CAPE administration. Ak et al. found favorable results of systemic CAPE administration in $\mathrm{SCl}$ (1). They reported that CAPE contributes to the healing process by suppressing the levels of pro-inflammatory cytokines. In addition, Aydin et al. observed that intraperitoneal CAPE administration had a positive effect on spinal cord injury models by preventing apoptosis (2). No previous studies have evaluated the effects of intrathecal CAPE administration on IL-6 and TNF-a levels following traumatic SCl as well as on inflammation-induced edema and microhemorrhage. Because of the damage directly caused by trauma on the spinal cord and surrounding tissues and because of inflammation-induced impairment of tissue perfusion, it is difficult for systemically administered pharmacological agents to reach a maximum effective dose in the damaged area. Therefore, we preferred the use of intrathecal drug administration in this study; this is an alternative approach for managing central nervous system diseases. One aspect in which our study differed from the existing literature is the evaluation of the effect of intrathecal CAPE administration on inflammatory cytokines and on local histopathological changes caused by inflammation during spinal cord injuries.
In our study, it was observed that CAPE administration following $\mathrm{SCl}$ led to a decrease in tissue and serum levels of IL-6, which is an inflammatory cytokine that plays a significant role in secondary damage. However, CAPE was not found to be as effective as MP in decreasing IL-6 levels. Furthermore, the decreases observed in tissue and serum TNF-a levels following CAPE and MP administration were not significant. In addition, it was observed that CAPE led to a significant decrease in the edema and microhemorrhage that developed in association with a local inflammatory response in the damaged area. In fact, although MP was not shown to have any effect in decreasing microhemorrhage, the effect of CAPE in decreasing bleeding was apparent. When posttraumatic $\mathrm{SCl}$ anti-inflammatory activities were evaluated, it was determined that MP was more effective than CAPE in decreasing IL-6 levels, whereas CAPE was more effective in decreasing microhemorrhage in the damaged area. If similar studies support our findings in the future, the use of CAPE along with MP for decreasing microhemorrhage during $\mathrm{SCl}$ treatment should be considered. Future research using CAPE in different dosages and/or with different time intervals is required to support our findings. The application of different dosages could affect the cytokine levels and associated local inflammatory responses. This may be a limitation of our study.

\section{CONCLUSION}

CAPE can contribute to a decrease in tissue and serum levels of the inflammatory cytokine IL-6, which plays an important role in secondary damage associated with $\mathrm{SCl}$, and to a decrease in spinal cord edema and microhemorrhage. However, these results need to be supported by further studies. 


\section{ACKNOWLEDGEMENTS}

Preparation for publication of this article was partly supported by the Turkish Neurosurgical Society.

\section{REFERENCES}

1. Ak H, Gulsen I, Karaaslan T, Alaca I, Candan A, Kocak H, Atalay T, Celikbilek A, Demir I, Yilmaz T: The effects of caffeic acid phenethyl ester on inflammatory cytokines after acute spinal cord injury. UTAD 21: 96-101, 2015

2. Aydin HE, Ozkara E, Ozbek Z, Vural M, Burukoglu D, Arslantas A, Atasoy MA: Histopathological evaluation of the effects of CAPE in experimental spinal cord injury. Turk Neurosurg 26: 437-444, 2016

3. Chen MF, Keng PC, Lin PY, Yang CT, Liao SK, Chen WC: Caffeic acid phenetyl ester decreases acute pneumonitis after irradiation in vitro and in vivo. BMC Cancer 5: 158, 2005

4. Gocmez C, Celik F, Kamasak K, Kaplan M, Uzar E, Arikanoglu A, Evliyaoglu O: Effects of intrathecal caffeic acid phenethyl ester and methylprednisolone on oxidant/antioxidant status in traumatic spinal cord injuries. J Neurol Surg A Cent Eur Neurosurg 76: 20-24, 2015

5. Ilhan A, Koltuksuz U, Ozen S, Uz E, Ciralik H, Akyol O: The effects of caffeic acid phenethyl ester (CAPE) on spinal cord ischemia/reperfusion injury in rabbits. Eur J Cardiothorac Surg 16: 458-463,1999
6. Isogai $\mathrm{E}$, Isogai $\mathrm{H}$, Kimura $\mathrm{K}$, Hayashi $\mathrm{S}$, Kubota $\mathrm{T}$, Fujii $\mathrm{N}$, Takeshi K: Role of tumor necrosis factor alpha in gnotobiotic mice infected with an Escherichia coli O157:H7 strain. Infect Immun 66: 197-202, 1998

7. Juurlink $\mathrm{BH}$, Paterson PG: Review of oxidative stress in brain and spinal cord injury: Suggestions for pharmacological and nutritional management strategies. J Spinal Cord Med 21: 309-334, 1998

8. Kasai M, Fukumitsu H, Soumiya H, Furukawa S: Caffeic acid phenethyl ester reduces spinal cord injury-evoked locomotor dysfunction. Biomed Res 32:1-7, 2011

9. Korkmaz HA, Maltepe F, Erbayraktar S, Yilmaz O, Guray M, Canda MS, Gunerli A, Gokmen N: Antinociceptive and neurotoxicologic screening of chronic intrathecal administration of ketorolac tromethamine in the rat. Anesth Analg 98: 148-152, 2004

10. Kurt G, Ergun E, Cemil B, Borcek AO, Borcek P, Gulbahar O, Ceviker N: Neuroprotective effects of infliximab in experimental spinal cord injury. Surg Neurol 71: 332-336, 2009

11. Wiig $\mathrm{H}$ : Pathophysiology of tissue fluid accumulation in inflammation. J Physiol 589: 2945-2953, 2011

12. Yaksh TL, Rudy TA: Chronic catheterization of the spinal subarachnoid space. Physiol Behav 17: 1031-1036, 1976

13. Zheng $H$, Crowley JJ, Chan JC, Hoffmann H, Hatherill JR, Ishizaka A, Raffin TA: Attenuation of tumor necrosis factor-induced endothelial cell cytotoxicity and neutrophil chemiluminescence. Am Rev Respir Dis 142: 1073-1078, 1990 